University of Nebraska - Lincoln

DigitalCommons@University of Nebraska - Lincoln

Faculty Publications in Educational

Administration

Educational Administration, Department of

2020

Belonging in a Predominantly White Institution: The Role of

Membership in Latina/o Sororities and Fraternities

Crystal Garcia

Follow this and additional works at: https://digitalcommons.unl.edu/cehsedadfacpub

Part of the Educational Administration and Supervision Commons

This Article is brought to you for free and open access by the Educational Administration, Department of at DigitalCommons@University of Nebraska - Lincoln. It has been accepted for inclusion in Faculty Publications in Educational Administration by an authorized administrator of DigitalCommons@University of Nebraska - Lincoln. 


\title{
Belonging in a Predominantly White Institution: The Role of Membership in Latina/o Sororities and Fraternities
}

\author{
Crystal E. Garcia \\ Auburn University \\ Correspondence/Current address - Crystal E. Garcia, Department of Educational Admin- \\ istration, College of Education and Human Sciences, University of Nebraska-Lincoln, \\ Lincoln, NE 68588; email crystalgarcia@unl.edu
}

\begin{abstract}
This qualitative, multiple case study explored the role of involvement in a particular university subculture, Latina/o sororities and fraternities, in how Latina/o college students develop and make meaning of their sense of belonging within predominantly White institutions. Findings address ways Latina/o college students described their institutional sense of belonging in addition to a discussion of five primary characteristics of belonging: where I have a role or responsibility, where people look like me, where I am valued and cared for, where my racial identity and culture is recognized and valued, and where I share interests or values with others. The results underscore the significance of the role of belonging in campus subcultures for Latina/o college students. Implications for research and practice are discussed.
\end{abstract}

Keywords: Latina/o college students, fraternity and sorority life, sense of belonging, culturally based organizations, campus subcultures

Published in Journal of Diversity in Higher Education 13:2 (2020), pp 181-193.

doi:10.1037/dheoooo126

Copyright (C) 2019 National Association of Diversity Officers in Higher Education. Published by American Psychological Association. Used by permission. "This paper is not the copy of record and may not exactly replicate the version published in the APA journal."

Submitted September 6, 2018; revised March 25, 2019; accepted May 4, 2019; published May 30, 2019. 
"It's a privilege to feel like you belong everywhere and you know that you can go anywhere and see people who look similar to you." (Juan)

Juan's statement underscores the roles of privilege and racial/ ethnic identity in sense of belonging-"students' perceived social support on campus, a feeling or sensation of connectedness, the experience of mattering or feeling cared about, accepted, respected, valued by, and important to the group (e.g., campus community) or others on campus (e.g., faculty, peers)" (Strayhorn, 2012, p. 3). Sense of belonging can affect well-being (Hagerty, Williams, Coyne, \& Early, 1996), motivate behavior (Strayhorn, 2012), and promote positive academic outcomes for college students (Hausmann, Schofield, \& Woods, 2007). The close ties between sense of belonging and the concepts of marginalization and mattering for college students means that sense of belonging may also be a strong indicator of inclusivity and equity within postsecondary environments (Rosenberg \& McCullough, 1981; Schlossberg, 1989).

Like Juan, the literature has highlighted the roles of privilege, race, and ethnicity in sense of belonging. Johnson and colleagues (2007) found that students differed by race in regard to elements that affected sense of belonging while Johnson et al. (2007) and Strayhorn (2008) found that when compared to their White peers, Students of Colorincluding Latina/o/ $\mathrm{xs}^{1}$-were more likely to experience a lower sense of belonging. In Vaccaro and Newman's (2016) study of how college students develop a sense of belonging, students with privileged identities-“those who identified as White, Christian, middle/upper class, heterosexual, or an individual without a disability" (p. 925)-differed in how they made meaning of the term sense of belonging when compared to students with minoritized identities. While both groups of students identified "being comfortable" and "fitting in" as descriptors of sense of belonging, minoritized students also espoused "safety and respect" as components of sense of belonging (p. 937). Thus, even beyond the role of privilege, race, and ethnicity in sense of belonging, these findings also point to important considerations for campus

1. I use Latina/o/x(s) as a gender inclusive term to refer to members of this community while Latina/o is used in reference to sororities and fraternities and their membership within this study, which have historically excluded individuals that do not identify in the gender binary. 
climates in terms of cultivating spaces in which students feel safe and respected across difference.

Considering the intersecting dynamics of race, ethnicity, privilege, equity, and inclusivity that has been illuminated in sense of belonging studies and the educational disparities experienced by racially minoritized populations such as Latina/o/xs (Ryan \& Bauman, 2016), these differences warrant a closer examination of influences that distinguish the experiences of Latina/o/x students from their White peers. Yet, a majority of the literature on college student sense of belonging focuses on institutional level of belonging as opposed to the role of campus subcultures (Dueñas \& Gloria, 2017; Hurtado \& Ponjuan, 2005; Nuñez, 2009). While some sense of belonging models have included subcontexts of the institution such as residence halls, living-learning communities, and classes (Freeman, Anderman, \& Jensen, 2007; Johnson et al., 2007; Spanierman et al., 2013), they have not examined the degree of importance students place on sense of belonging to subcontexts independent of their belonging to the institution.

Ethnic-based student organizations are a particular campus subculture and form of collective cultural agent that have been examined in the literature and can play an important role in the experiences of Latina/o/x college students (González, 2002; Kim, Park, \& Koo, 2015; Luedke, 2018; Museus, 2008b; Villalpando, 2003). Ethnic student organizations may take the form of "fraternities and sororities open solely to membership among one racial/ethnic group, cultural groups that celebrate one specific racial or ethnic heritage, and activist organizations that concentrate on political interests for a certain race or ethnicity" (Inkelas, 2004, p. 285).

Latina/o sororities and fraternities are one particular form of ethnic-based organizations that have been connected to positive student outcomes (Atkinson, Dean, \& Espino, 2010; Delgado- Guerrero \& Gloria, 2013; Guardia \& Evans, 2008; Sanchez, 2011). Similar to historically White sororities and fraternities, these organizations are encompassed within fraternity and sorority life (FSL) communities and have a unique culture that distinguishes these groups from other types of student organizations including the adoption of symbols such as organizational colors and mascots, secret rituals, an abidance by rules set forth by the local and national organizational governance, engagement in the campus community and philanthropic activities, and a 
focus on the notions of brotherhood and sisterhood (Muñoz \& Guardia, 2009; Torbenson, 2005).

The findings from studies focused on the role of culture and campus subcultures (Museus, 2008b; Museus \& Quaye, 2009) and specifically the unique experiences of Latina/o/xs in relation to campus subcultures (Attinasi, 1989; González, 2002) provide reason to believe that belonging to a campus subculture may in fact be equally if not more important to Latina/o/x college student experiences than belonging at the institutional level. Thus, this study explored the role of involvement in a particular university subculture, Latina/o sororities and fraternities, in how Latina/o college students develop and make meaning of their sense of belonging within predominantly White institutions (PWIs). The following questions guided this research:

1. How do Latina/o college students involved in Latina/o sororities and fraternities at PWIs experience and develop a sense of belonging?

2. What role (if any) does involvement in Latina/o sororities and fraternities play in how Latina/o college students experience and develop a sense of belonging at PWIs?

\section{Literature Review}

To provide context for the focus of this study, this section will first explore literature centered on the roles of racial/ethnic identity in relation to sense of belonging. It then presents the case for focusing on the role of campus subcultures in relation to sense of belonging and concludes with a discussion of ethnic-based organizations and Latina/ $\mathrm{o} / \mathrm{x}$ organizations specifically as a form of campus subculture.

\section{Racial/Ethnic Identity and Sense of Belonging}

The literature on campus climates for diversity provides useful insight to how and why experiences with sense of belonging on college campuses differ for Latina/o/xs than for their White peers, particularly when acclimating to PWIs. Researchers have found that perceptions of a hostile climate (Nuñez, 2009), perceptions of racial-ethnic 
tensions (Hurtado \& Carter, 1997), and perceptions of a negative climate for diversity (Hurtado \& Ponjuan, 2005) have all been connected to lower sense of belonging for Latina/o/xs. In addition, students from backgrounds that differ significantly from the dominant campus culture, such as Students of Color, face unique challenges in developing a sense of belonging within the campus community (Museus, 2008a; Museus \& Quaye, 2009).

Colleges are shaped by unique institutional cultures, yet students enter these spaces with their own individual cultural backgrounds and experiences (Kuh \& Love, 2000). As a result, when students enter college environments, conflict can arise from the differences between student culture and the dominant campus culture, an experience called cultural dissonance (Museus, 2008b) or a lack of cultural fit (Gloria, Castellanos, \& Orozco, 2005). Cultural dissonance may contribute to cognitive dissonance and can be experienced by all entering college students, but particularly so for Students of Color (Museus, 2008a). Cultural dissonance functions as an added stressor as college students navigate campus environments and may serve as an obstacle to student persistence (Museus \& Quaye, 2009).

Although PWIs are not the only institutions that experience issues with negative campus climates, research has called attention to the particular challenges with hostile climates for diversity and racial tensions that affect Students of Color enrolled in these institutions (Hurtado \& Carter, 1997; Locks, Hurtado, Bowman, \& Oseguera, 2008). Furthermore, the extent to which Students of Color experience pressure to commit cultural suicide and "sever ties with their cultural heritage or their cultural identities and conform to their campus cultures" (Museus \& Maramba, 2011, p. 242) may also be more salient at PWIs (Museus \& Maramba, 2011).

\section{The Role of Subcultures in Sense of Belonging for Students of Color}

Within college and university culture are student subcultures such as "institutions, major fields, social clubs or organizations, and social-oriented affinity groups" (Kuh \& Love, 2000, p. 199). The cultural propositions developed by Kuh and Love (2000) and the subsequent intercultural propositions created by Museus and Quaye (2009) 
highlight ways campus subcultures may facilitate the development of a sense of belonging for Students of Color. In particular, Museus and Quaye's (2009) fifth intercultural proposition asserted that individual and collective cultural agents:

provide students with smaller and more manageable environments within the larger campus, offer a conduit for socialization into the larger campus community, and provide a venue in which students can maintain and express a sense of racial/ethnic identity on campus. (Museus \& Quaye, 2009, p. 72)

Though not explicitly tied to sense of belonging, this proposition asserts that cultural agents can assist Students of Color as they navigate college environments and maintain a connection to their cultural backgrounds. Though the proposition noted that cultural agents can serve to conjoin students to the greater campus environment, it is reasonable to consider that these campus subcultures offer a place for students to belong regardless of their effect on student ties to the campus as a whole. This rationale underscores the possibility that a student could develop a sense of belonging within a campus subculture without feeling a sense of belonging to the greater campus community. Though this distinction may seem like a matter of semantics, there is a critical difference that warrants further investigation.

The importance of subcultures was also reflected in Attinasi's (1989) study of the experiences of Mexican American college students. Participants described their early perceptions of a sense of "bigness" (p. 262) in relation to the complexity of the social, physical, and academic geography of the institutions and adopted the strategy of "scaling down" (p. 263) the complexities of campuses by connecting to smaller spaces including subcultures of the university such as academic departments. Given this finding, it stands to reason that for some Latina/o/x students, sense of belonging in subcultures may in fact be more critical to their college experiences than a sense of belonging at the institutional level. 


\section{Ethnic-Based Organizations as Campus Subcultures}

A particular form of campus subculture that may play a role in sense of belonging for Students of Color are ethnic-based organizations. Some researchers have argued the notion that racial balkanization, a tendency for Students of Color to self-segregate into their respective racial groups, creates negative effects on various cognitive and affective outcomes for Students of Color (D'Souza, 1991; Sidanius, Van Laar, Levin, \& Sinclair, 2004). While some researchers have argued that ethnic-based organizations serve as ethnic enclaves that prevent cross-cultural interactions, Kim et al. (2015) found that involvement in ethnic-based student organizations was directly and positively connected to interracial friendships exclusively for Latina/o/x students compared to students with other racial identities.

Other research has also documented benefits of ethnic-based organizations for Latina/o/xs (Luedke, 2018; González, 2002; Villalpando, 2003). Luedke (2018) examined ways Latinx student organizations influenced students' collegiate experiences and found that the organizations provided a sense of familia (family) and served as a source of capital that helped them to successfully navigate their academic experience. Villalpando's (2003) study of Chicana/o college students concluded that involvement in a Chicana/ o peer group "reaffirmed" the value of their culture and provided a way for students to maintain ties to their Chicana/o communities. Similarly, participants in González's (2002) study reported that the lack of Chicanos and any physical representation of Chicanos on campus led to feelings of "marginalization and alienation" (p. 202). One important way participants found "cultural nourishment" in spite of the "alienation" (p. 211) they felt from the greater campus community was through involvement in a Chicano organization. Given these findings, for some students, developing a sense of belonging within a smaller aspect of the campus community, such as an academic major or campus organization, can be equally if not more important than a sense of belonging to the campus as a whole.

Latina/o sororities and fraternities are both ethnic-based organizations and Greek letter organizations, simultaneously offering a source of brotherhood and sisterhood (Delgado-Guerrero \& Gloria, 2013; Sanchez, 2011) while supporting ethnic identity development (Guardia 
\& Evans, 2008). The dual nature of these organizations as Greek letter and ethnic-based organizations means that these groups embody the purposes of both organizational types by providing a brotherhood/sisterhood that offers members support as they adjust to the college environment and simultaneously embraces the Latina/o/x culture (Moreno, 2012; Sanchez, 2011). This was exemplified in Moreno's (2012) exploration of the academic experiences of Latinas in a Latinabased sorority at a large public research institution. Participants in this dissertation study described the development of a sisterhood that went deeper than typical friendships. The sisterhood bond was based on shared values, provided support to the participants, and served as a "family away from home" (p. 46). The explicit focus sororities and fraternities place on the concept of family define these organizations as distinct from other ethnic-based organizations and may be particularly important in Latina/o/x students' sense of belonging (Kiyama, Museus, \& Vega, 2015). Although the literature focused on Latina/o sororities and fraternities is limited, findings to date underscore the potential influence these organizations may play in students' development of belonging within predominantly White institutions.

\section{Conceptual Framework}

Conceptual frameworks are distinct from theoretical frameworks in that they do not rely on a single theory, but connect multiple concepts together to understand a phenomenon (Imenda, 2014). The conceptual framework for this study included Strayhorn's (2012) definition of sense of belonging along with components of two ecological theories to further probe the element of context in Latina/o college student sense of belonging. Strayhorn's (2012) definition alludes to the primary way researchers have considered sense of belonging in relation to college students-by way of exploring how sense of belonging to the campus is connected to student outcomes and by examining influences that shape a student's perceived sense of belonging within the campus community. Strayhorn's (2012) definition as well as the literature on sense of belonging underscores the notion that the development of a sense of belonging is highly contextual. Therefore, to further probe the role of context I used Bronfenbrenner's (1995, 1997) 
ecological systems theory to identify environmental structures that may affect students' sense of belonging.

Bronfenbrenner's (1997) topology of environmental structures includes the microsystem, "pattern of activities, roles, and interpersonal relations experienced by the developing person in a given face-to-face setting" (p. 307); the mesosystem, the linkage between two or more microsystems; the exosystem, which also consists of two or more settings; however, the individual is not contained within at least one of these settings yet occurrences within that setting has an indirect effect on the individual; and the macrosystem, which is "the overarching pattern of micro-, meso-, and exosystems characteristic of a given culture, subculture, or other extended social structure" (p. 317). The chronosystem represents time and involves "the historical period in which the person lives" (Bronfenbrenner, 1995, p. 641).

I used Bronfenbrenner's environmental structures as a first step to parse the role of context in student experiences. However to further interrogate student experiences within these systemic levels in light of the postsecondary environments they were situated within, I also considered Strange and Banning's (2015) four models of human environments-the physical, aggregate, organizational, and socially constructed environments. The physical environment includes "the built environment" (p. 12), while aggregate environments are made up by the characteristics of the individuals within those environments. Organizational environments include how institutions are constructed and ways power and responsibilities are distributed to achieve goals. Socially constructed environments "focus on the collective subjective views and experiences of participant observers" (p. 116).

\section{Method}

Using a multiple case study design (Stake, 2006), this study explored the role of involvement in an institutional subculture, Latina/o sororities and fraternities, in how Latina/o college students develop and make meaning of their sense of belonging within PWIs. A case study is "an intensive, holistic description and analysis of a single, bounded unit" (Merriam, 2001, p. 194), whereas a multicase study examines multiple cases in order to more fully understand the phenomenon of 
interest (Stake, 2006). Merriam (2001) added that "case study is a particularly suitable design if you are interested in process" (p. 33), which aligned well with the scope of this study as I sought to understand how students developed belonging.

Cases in a multiple case study should be selected based on what they can reveal about the phenomenon (Stake, 2006). I reasoned that if it was possible for a student to feel belonging within a subculture without belonging to the campus as a whole-this may be more likely in relation to culturally rich subcultures-then members of Latina/o sororities and fraternities may be considered information-rich cases. Therefore cases were bound as individuals, wherein each case was a Latina/o-based sorority or fraternity member. Bounding cases on the individual level was useful in examining the unique nature of each participant's experience while maintaining the ability to look across cases (Stake, 2006).

Distinct from other methodological approaches, case study does not defer to a particular form of data collection and analysis; "any and all methods" can be adopted (Merriam, 2001, p. 28). My research approach was informed by my critical constructivist paradigm. Critical research involves "challenging power relations both in the world and in the research process itself" (Merriam \& Tisdell, 2016, p. 64). Though I believe multiple realities exist and that each person creates and experiences his or her own reality, I also believe that social structures influence the development of those realities. To recognize these dynamics within data analysis, I incorporated elements of a constructivist grounded theory approach.

Grounded theory methods can effectively accompany other qualitative methods (Charmaz, 2006). Though this is not a pure grounded theory study, incorporating aspects of a constructivist grounded theory approach in my data collection approach and analysis helped to make sense of the multiple case study data in light of my critical constructivist paradigm. Borrowing from grounded theory, I used sensitizing concepts including previous literature and frameworks to develop the conceptual framework and used these as "a place to start, not to end" (Charmaz, 2006, p. 17). My use of sensitizing concepts will be further described within the Data Collection and Data Analysis sections. 


\section{Participant Selection}

Case studies are ideal approaches to uncover contextual nuances (Maxwell, 2013). For multiple case studies, "the more cases included in a study, and the greater the variation across the cases, the more compelling an interpretation is likely to be" (Merriam, 2001, p. 40). In an effort to further explore the role of context in participant experiences and obtain greater variation across cases, I chose to recruit participants from two institutions that shared similar characteristics to compare and contrast their experiences within those environments. The institutions, Plains University and Clearview University (pseudonyms), are both large public R1 universities located in Midwestern states. White students comprised just over $70 \%$ of the enrollment at Plains University and 75\% at Clearview University, while Latina/o/x students made up approximately $5 \%$ of the population at both. Interviews with FSL staff members provided contextual details regarding the FSL community at each university. Just under $17 \%$ of the undergraduates at Plains and over $20 \%$ at Clearview were involved in FSL. There were nearly 50 National Panhellenic Conference (NPC) and North American Interfraternity (IFC) organizations, seven National Pan- Hellenic Council (NPHC) organizations, and approximately 10 Multicultural Greek Council (MGC) organizations at Plains. Clearview University had nearly 40 NPC and IFC, four NPHC, and four MGC organizations. Latina/o sororities and fraternities were grouped within the MGC organizations at both institutions.

Participant recruitment was conducted after receiving IRB approval through a purposeful selection process (Maxwell, 2013). I aimed to enlist an even mix of women and men participants as well as representation from different FSL organizations. The Latina/o sororities and fraternities included in this study ranged in size from an estimated five to 16 members. Active membership entailed being in good standing with the organization; therefore, when participants were unsure of the exact number of active members in the chapter they provided their best estimate. Fifteen individuals agreed to participate in this study; however, one individual chose not to continue after the first interview. Final participants included 14 Latina/o sorority and fraternity members, including eight that identified as women and six as 
Table 1. Participant Demographics

\begin{tabular}{|c|c|c|c|c|c|}
\hline Pseudonym & Organization & $\begin{array}{l}\text { Semesters in } \\
\text { University }\end{array}$ & Age & Race/Ethnicity & Major \\
\hline \multicolumn{6}{|c|}{ Plains University } \\
\hline Christina & Kappa Beta & 3 & 19 & Mexican & Apparel Design \\
\hline Davina & Kappa Beta & 3 & 19 & Mexican & Civil Engineering \\
\hline Nine & Kappa Beta & 7 & 21 & Latina & Psychology \\
\hline Paloma & Kappa Beta & 3 & 19 & Mexican & Kinesiology and Health \\
\hline Delta & $\mathrm{Nu}$ Sigma & 7 & 25 & Hispanic/Latino & Mechanical Engineering \\
\hline Romeo & Nu Sigma & 5 & 20 & Hispanic & Civil Engineering \\
\hline Fernando & Omega Iota & 5 & 20 & Hispanic & Mechanical Engineering \\
\hline Hector & Omega Iota & 3 & 19 & Mexican-American & Computer Engineering \\
\hline Juan & Omega Iota & 7 & 21 & Mexican-American & Environmental Science \\
\hline \multicolumn{6}{|c|}{ Clearview University } \\
\hline Karla & Pi Delta & 3 & 19 & Mexican & Biochemistry \\
\hline Lori & Pi Delta & 5 & 20 & Hispanic & Nutrition \& Exercise Science \\
\hline Participant 01 & Pi Delta & 7 & 21 & Latina & Human Development and Family Science \\
\hline Omi & Pi Delta & 5 & 20 & Mexican-American & Elementary and Special Education \\
\hline Luis & Zeta Alpha & 7 & 21 & Latino & Latin American/Global Studies \\
\hline
\end{tabular}

men. Table 1 provides additional participant demographic information listed alongside pseudonyms they selected.

When joining a Latina/o sorority or fraternity, students engage in a new-member education process that varies in length by organization and typically takes place over the duration of a semester. Members "cross" or officially become active members following this process. Eight of the participants were in their first or second active semester after crossing. The other six members were in their third semester or beyond as active members. All participants but one held formal officer roles within their chapter at some point in their membership.

\section{Data Collection}

Case studies often rely on multiple data collection methods to understand the phenomenon of interest (Stake, 2006). I collected individual data to gain insight to participants' lived experiences and institutional data to further understand the contexts they were situated in that shaped those experiences. Organizational data included institutional documents such as enrollment demographics as well as a review 
of the FSL websites and an interview with members of each university's FSL staff. Interviews with FSL professionals focused on the size, scope, and culture of FSL at each institution. Individual data included demographic surveys and a series of three semistructured interviews (Creswell, 2013) ranging from approximately 35 min to an hour and 10 min with each participant. I chose to engage participants in a series of three interviews to build rapport with my participants and to make use of the spans of time between each interview for myself and the participants to engage in reflection about their experiences. I realized this may have limited who chose to participate in this research, but I felt the benefits outweighed this limitation. Importantly, as a result of my critical constructivist approach, I strived to make sense of participants' individual lived experiences while uncovering ways social structures have influenced these experiences.

Questions for Interview 1 were largely drawn from the conceptual framework. The interview focused on participant experiences as they began at their university and became involved in their sorority/fraternity as well as participants' sense of belonging within the institution as a whole, within the organization, and ways the two influenced one another. Examples of questions in this interview included: Can you think of a time when you felt a sense of belonging within your Latina/o sorority or fraternity when you first joined? What was it about the organization that made you feel that way? Do you currently feel a sense of belonging within the greater campus community here at $\mathrm{x}$ university? Are there specific aspects of the campus that make you feel that way?

Although I heavily relied on sensitizing concepts (Charmaz, 2006) to construct the first interview protocol, the second and third interviews were largely guided by participants through the use of photo elicitation-the use of photographs in an interview setting (ClarkIbáñez, 2004; Harper, 2002). As reflected in the design of Research Question 1, I was interested in first exploring students' overall sense of belonging. Therefore, students were encouraged to bring pictures to discuss of places on and off campus they felt a sense of belonging in and places they did not. While the photos centered the conversation on participants' lived experiences, I remained attentive to the conceptual framework, following up with questions as applicable concerning aspects of the microsystem, mesosystem, exosystem, and macrosystems 
that played a role in participants' sense of belonging. Furthermore, photos were used as a prompt to probe what it was about those contexts-particularly the physical, aggregate, organizational, and socially constructed environments (Strange \& Banning, 2015) -that contributed to sense of belonging.

\section{Data Analysis}

In a multiple case study, each case is given attention in analysis, yet the ultimate question revolves around developing an understanding of the phenomenon of interest (Stake, 2006). Analysis first involved a review of institutional level data to deepen my understanding of the institutional and organizational context; however, primary analysis was at the individual level, beginning with within-case analysis. The conceptual framework was used as a sensitizing concept that informed the construction of the interview protocols and was also used as a guide during data analysis while remaining open to other interpretations (Charmaz, 2006). During analysis I also remained cognizant of the duality of the "creation of knowledge by the viewer and the viewed" (Charmaz, 2000, p. 510).

In first cycle coding, I made sense of each participant's experiences by analyzing transcripts through line-by-line coding with particular attention to elements from the conceptual framework including environments, events, people, and time. I then developed case analysis documents that organized participant's "journey across time” with attention to "phases, stages, and cycles" (Miles, Huberman, \& Saldaña, 2014, p. 211). I conducted second cycle coding using these documents (Saldaña, 2016). While coding these documents I looked for evidence of participant experiences with and influences that played a role in the development of a sense of belonging in light of the conceptual framework and for any ways participant experiences departed from these concepts. After generating a list of codes, I developed a system of code grouping and naming the code categories. I then employed axial coding to identify relationships among the categories and subcategories and refined these in a more succinct way (Saldaña, 2016). Following within-case analysis, I then turned my attention to the collection of cases during cross-case analysis (Merriam, 2001). I used categories and subcategories resulting from axial coding to explore similarities 
and differences across participant experiences and to identify central themes using composite sequence analysis (Miles et al., 2014)-a network display of student experiences.

\section{Reliability and Reflexivity}

Multiple methods were used to ensure the trustworthiness of this research including the use of a multiple case study approach (Merriam, 2001) and the adoption of a purposeful participant selection process. Data was triangulated through the use of multiple data sources (Moore, Lapan, \& Quartaroli, 2012). Rather than using this approach as a measure of ensuring the validity of findings, triangulation was used to obtain a wider span of data in an effort to produce a more complex explanation of the phenomenon. Member checking was also used to solicit feedback from participants regarding the case analysis documents. All 14 participants were sent their individual case analysis for review; two individuals offered clarifying details and approved the documents, three approved the documents as written, and the other nine chose not to participate.

Finally and importantly, I remained reflexive of my positionality and influence on the study (Merriam \& Tisdell, 2016). Qualitative researchers play an important role in the research process and contribute to the construction of knowledge, which is why it is important for researchers to acknowledge the perspectives, assumptions, and subjectivity they enter research with (Charmaz, 2006). I approached this research recognizing my experiences as a multiracial, White and Latina woman, a first-generation college student, a member of an NPC sorority, and a previous student affairs administrator. I remained cognizant of my own subjectivity, but also recognized it cannot be completely removed from the research process (Maxwell, 2013). However, I also bring experiential knowledge through my understanding of FSL and Latina/o/x culture, which was instrumental during data collection and analysis. Although my knowledge of fraternity and sorority life was helpful in understanding FSL culture and organizational nuances, my understanding of Latina/o/x organizations stems from reading rather than first-hand experience. While I did not share the experience of being a member of these organizations, I was intentional in educating myself about them. I believe my positionality helped me 
to establish rapport with the participants in this study; however, my position as an insider-outsider also meant that I did not always share perspectives or experiences with participants.

\section{Findings and Discussion}

Whether participants felt a sense of belonging within their institutions overall was more complex than a simple yes or no. There were essentially four categories of responses to this question- those that did not feel a sense of belonging; those whose sense of belonging was murky; those that felt a sense of belonging and discussed their belonging in relation to their subcommunities; and those that felt a sense of belonging, but primarily attributed their belonging to the fact they were a student working toward an academic goal. Importantly, the differences in how participants described their sense of belonging is notable because even for participants that reported feeling a sense of belonging to the university, many still identified particular microsystems on campus that they did not feel a sense of belonging within.

Knowing whether individuals felt that they belonged on campus and within their organizations was a first step, however this study primarily sought to explore how participants experienced and developed a sense of belonging and what role their involvement in sororities and fraternities played in the development of sense of belonging. An analysis of spaces participants identified as places they felt a sense of belonging and places they did not resulted in five characteristics of places of belonging: where I have a role or responsibility, where people look like me, where I am valued and cared for, where my racial identity and culture is recognized and valued, and where I share interests or values with others. These characteristics shaped the extent to which participants felt a sense of belonging within a given microsystem, which also played a role in other systemic levels (Bronfenbrenner, 1997).

The following sections offer an integrated discussion of these findings in relation to previous literature and the conceptual framework by first discussing ways participants described their sense of belonging to the institution. It then addresses each of the characteristics of belonging, describing how these played a role in participant experiences 
generally and then specifically in relation to their Latina/o sororities and fraternities. These examples are not intended to assert that characteristics of belonging manifested singularly; rather, in most scenarios participant sense of belonging was a result of an overlap of several characteristics. These sections simply aim to highlight important ways the characteristics of belonging played a role in shaping participant sense of belonging.

\section{Institutional Sense of Belonging}

As previously mentioned, there were essentially four different ways that participants described their institutional sense of belonging, which adds to previous literature on how students make meaning of the term belonging (Vaccaro \& Newman, 2016). While Vaccaro and Newman identified nuances in descriptors students associated with belonging, these findings provide insight to ways students distinguished belonging within institutional and organizational contexts. The first group of students included three participants- Fernando, Paloma, and Romeo. These individuals described lacking a sense of belonging in the university as a whole, but noted that they belonged in one or more subcultures within the university. For instance, Fernando believed he felt more of a sense of belonging within the outreach programs his fraternity worked with as opposed to the greater university, adding, "I don't feel like they do enough for People of Color on campus." Paloma juxtaposed her sense of belonging within the institution with how she felt about her community. She reflected, "I feel comfortable within the community I'm a part of and the community I decide to be involved with, but maybe not so much with the community as a whole." Romeo did not feel a sense of belonging within the greater campus community noting, "If I disappeared I don't think anybody would have noticed."

Two participants, Christina and Nine, were in the next category, where their sense of belonging within the university as a whole was murky, but they still had a sense of belonging in one or more subcultures. Both of these individuals expressed that it was difficult to feel a sense of belonging within the greater community when campus climate issues were occurring at Plains, pointing to the influence of the macrosystem and chronosystem (Bronfenbrenner, 1997) in 
participants' belonging. Overall Nine thought "the campus climate has been a little more sticky especially now with the election coming up," and as a result was unsure of whether she really felt that she belonged at Plains. Given the time period these data were collected within, the sociopolitical context played an important role in students' experiences. Students of Color and other marginalized populations were the focus of then presidential candidate Trump's political messaging and, as a result, these aggressions were mirrored on college campuses.

In the next category, seven of the participants-Delta, Hector, Karla, Luis, Participanto1, Lori, and Davina-asserted that they felt a sense of belonging within the university, but discussed their sense of belonging in terms of their communities, which reflected ways individuals inherently linked their experiences within microsystems with their perceptions of the macrosystem (Bronfenbrenner, 1997). Hector thought it was "tough" to think of a time when he felt as if he did not belong within the greater campus community because he had his fraternity and "most of the time I'm with them . . . so it's kind of hard not to feel that sense of belonging." In the final category of responses, Juan and Omi responded that they felt a sense of belonging on campus, but answered primarily in terms of their belonging academically as students in the institution. Juan believed he belonged to the university as a whole because "I belong academically and that's what the university should be based on." Juan and Omi's responses were distinct from the others in that they relied on their identities as students as the rationale for their belonging as opposed to an affective perspective.

\section{Where People Look Like Me}

Being in places "where people look like me" was a clear reflection of the aggregate environment (Strange \& Banning, 2015) and perhaps the most significant influence on participants' sense of belonging because it was a visible way individuals were able to identify with others and know that they shared similar backgrounds and experiences. As Fernando described, when he saw that he was the only or one of few Latina/o/xs in a given setting, "I just feel excluded." Similar to González's (2002) findings that a lack of Chicano representation on campus caused participants to feel "marginalization and alienation" 
(p. 202), as participants entered particular microsystems, a lack of other racially minoritized individuals within the setting often immediately caused them to question their belonging in that setting. For instance, Omi did not feel a sense of belonging in a green space near the Union because the individuals there were "always White people." She reflected, "I feel like if I would go with my friends to lay down or anything we would be outcasted. We would be looked down at in a way." In contrast, Omi thought a nearby patio area seemed "more welcoming for everyone because there I have seen more minorities." Like Omi, seeing other racially minoritized individuals or Latina/o/xs specifically was essential to participants' sense of belonging.

Membership in Latina/o sororities and fraternities was intrinsically connected to the characteristic "where people look like me." Although many of the participants emphasized that their organizations were inclusive of students from all backgrounds, not just Latina/os, all of the participants' decisions to join their fraternity or sorority was influenced by the organizations' service to the Latina/ o/x community and their primarily Latina/o member base. When Participanto1 transitioned to Clearview from a diverse high school, she questioned, "Where are the Latinos?" She described:

I definitely saw the difference between the population here. Like obviously since it is predominantly White it was kind of awkward walking around and being like, I do not see a familiar face. But I feel like it was more freshman year because we were new, we had no idea like where to go, where to meet people. So it was very overwhelming.

Similar to Vaccaro and Newman's (2016) findings that students from minoritized groups often felt isolated and sought out spaces in which they could be "their authentic selves" (p. 932), Participanto1 wanted to join a Latina-based sorority as opposed to other sororities because, "I feel like I wouldn't fit in [with the other sororities]. Like I couldn't fully be myself.” Whereas, she felt a sense of belonging within her sorority: "When I first joined. So from the very beginning I felt a sense of belonging because we were all Latinas, we were all mostly-it's Latina based. Like a lot of us spoke Spanish, so it was kind of easy." 
Being with others "who look like me" also played an important role in Delta's transition to Plains. Before enrolling, Delta went to Plains for a campus visit and he recalled,

I was so focused on finding other people that looked like me you know? And so not seeing a whole lot of diversity really freaked me out. I remember I was in the dining hall at Plains telling my mom I do not see any Latinos, I do not know if I want to come here.

Delta decided to continue with his plans to attend Plains, however things did not get better once he began his undergraduate experience there. Delta described,

My first 2 weeks were really difficult. I did not like it at all. I remember walking to my apartment and being close to breaking out in tears. I was not adjusting. Plains definitely has the resources to help you academically but I had pretty good study habits by then so academics was not an issue for me. The issue was actually having that social network at Plains. And since I didn't have that, I would just go to class, the library, go back home and read-I really was not getting too involved.

However after meeting the members of Omega Iota, Delta "saw a group of individuals where we all shared a common background, were all facing or had faced the same struggles, and we were all aiming to do something more." Delta even "met another guy who was actually from my same home state in Mexico . . . That was really neat just seeing more people like me." That was the point when Delta decided to join the fraternity and after that, "I really didn't face the same struggles I was facing my first 2 weeks. Sure I would get homesick every now and then, but nowhere to the same extreme as in my first 2 weeks." Finding a community where he saw aspects of himself reflected in the membership helped Delta to find a sense of belonging. 


\section{Where My Racial Identity and Culture Is Recognized and Valued}

Participanto1 attended an on-campus event her freshman year that featured culturally offensive skits including a "Mexican with a poncho and a sombrero." She reflected, "I had never really experienced like that stereotypical way of thinking until I got here I guess.” Although the Dean sent out an apology, nothing came from the students involved. While Participanto1 said she currently felt a sense of belonging within the community at Clearview, this was a particular occasion in which she felt that she did not belong. Her reflection on this event underscored the role of the characteristic "where my racial identity and culture is recognized and valued" in Latina/o student sense of belonging, a characteristic that was largely a reflection of the socially constructed environment (Strange \& Banning, 2015). Participants generally felt a sense of belonging in spaces where their racial and cultural identities as Latina/os and racially minoritized individuals were recognized or valued, whereas in spaces where they felt devalued implicitly or overtly as a racially minoritized person or Latina/o specifically, they did not feel they belonged.

Museus and Quaye (2009) argued that cultural agents could reduce the level of cultural dissonance experienced by individuals by validating "students' traditional cultural heritages" (p. 84). This was very much the case as participants did not seek to cut ties with their Latina/o/x cultural backgrounds, but rather intentionally sought out organizations to bolster those connections. Unlike some other areas on campus, the Latina/o sororities and fraternities provided participants with a space in which their racial identity and culture was always recognized and valued. Karla explained, "Our culture is very similar ... so we can all just relate to everything, which is not something I would be able to do with my other friends." For Karla, knowing that her culture was valued and that she could share aspects of her culture with her sisters was a critical component of her sense of belonging.

Importantly, the sororities/fraternities also served the Latina/o/x community through initiatives such as service and cultural events. There were two primary forms of these cultural events-those that celebrated and shared elements of Latina/o/x culture and those that were focused on bringing social justice issues faced by the Latina/ $\mathrm{o} / \mathrm{x}$ community to light. For instance, Delta shared that his fraternity 
brought speakers to campus that focused on cultural awareness for the Latina/o/x community including:

Jose Antonio Vargas who is an undocumented immigrant working for immigration reform . . . Bobby González who is a multicultural motivational speaker . . . and then we helped out with Denise Soler Cox who talked about Project Eñye, which [focuses on] individuals who grew up between two worlds and just kind of the struggles that we face as individuals because of it.

There were also important opportunities participants had to give back to their communities through service with the Latina/o sororities and fraternities such as Pi Delta's Conference for Young Latinas within the surrounding community and the Latina/o/x Family Day Nu Sigma members developed. Fernando described the Latina/o/x Family Day as:

Basically bringing college or high school students that are thinking about coming to the university. Basically giving them the same tour anybody else can receive, but we're more in depth with it when it comes to scholarships and things they should apply for or-like the same information you would get at any college visit day, except more detailed and catered more to the Latino students. Because it is all in Spanish.

All of the participants reflected on the positive role these events played in affirming the importance of their culture and contributing to their overall college experience and belonging.

\section{Where I Am Valued and Cared For}

Nine had a special relationship with her sorority advisor Dalihla, who “always greets me with 'hi mija [daughter] how are you?'." Nine reflected, "My mom always calls me that ... just that simple word ... [it] just makes you feel safer. It makes you feel like there's a place where you belong on campus." Nine's relationship with Dalihla was 
an example of how participants' sense of belonging was positively affected by feeling valued and cared for. This characteristic was reflective of the importance of mattering in relation to sense of belonging (Rosenberg \& McCullough, 1981). As Rosenberg and McCullough (1981) stated, mattering is "to believe that the other person cares about what we want, think, and do, or is concerned with our fate" (p. 164). Participants from both institutions reflected on the significance of the aggregate environment by way of university staff and faculty support in their sense of belonging.

There were several important ways that participants discussed the role of feeling valued and cared for in relation to their sense of belonging in their fraternity or sorority: through the concepts of brotherhood/sisterhood, being part of an interconnected network across the country, and the notion of membership for life. All of the participants reflected on the unique bonds they experienced through their sisterhood or brotherhood and its contribution to their sense of belonging within the organization. Many of these individuals noted that was one of the essential aspects of the organization that distinguished it from other types of groups, including other ethnic-based organizations.

The bonds of sisterhood and brotherhood were unique to FSL organizations and played an important role in why participants felt such a strong sense of belonging within their sororities and fraternities, mirroring previous literature on the significance of familial ties for Latina/o/x students (Kiyama et al., 2015; Luedke, 2018). The value of sisterhood was reflected, for instance, in Paloma's description of sisterhood as "family" and "somewhere where you can be safe, somewhere where you can be yourself . . . somewhere where you're always supported, somewhere you're always being watched out for.” Romeo's interpretation of brotherhood also illuminated the role of feeling cared for. He described:

[Brotherhood] means having each other's backs ... So taking a bullet for one another, literally and in the sense ofhow did you say it, sarcastically or something? . . . You're accepted no matter what ... We may disagree on an issue, but we'll work through it . . . just being there for that person in their best moments and their worst. 
Romeo noted that brotherhood was different than friendship because, "there's some things I would do for a brother that I wouldn't do for a friend . . . for a brother I feel like that's where I'd go the extra mile."

Participant descriptions of brotherhood and sisterhood strongly aligned with Moreno's (2012) findings that a Latina-based sorority served as a "family away from home" (p. 46) for the study's participants. Just as Moreno described, the familial concept was also a very salient component of the participants in this study and was often a term used to describe the bonds of brotherhood and sisterhood. The support the organizations provided was particularly critical for participants when they struggled. Romeo, for one, had received support that was vital to his college experience. He believed if he had never joined Nu Sigma, “I don’t feel like I would still be in college, I feel like I would've dropped out by now."

This culture of care and support manifested in a number of settings with the members of the sororities and fraternities such as chapter meetings and spaces frequented by members of the organization- including what the Kappa Betas called "Selena's spot" (partly named for the singer). Selena's spot reflected the significance of the physical environment (Strange \& Banning, 2015) in sense of belonging, The members all described this area of the library as a place that felt safe, comfortable, and where they belonged. Nine described, "It's just a place that we're always [at], if I'm going to the library, that's the first place I go to make sure if sisters are there." Yet she also noted, "If I have to study by myself I will just go to my apartment." Thus, the place was primarily important because of the people within it. Rather than holding importance in and of itself, the space served as a physical reminder of support offered by sisters.

\section{Where I Have a Role or Responsibility}

In addition to the human aggregate environment, "where I have a role or responsibility" is the central characteristic where aspects of Strange and Banning's (2015) organizational environmental dimension came into play and was an influential component of participant sense of belonging within organizations and formalized groups. Organizational environments are defined by goals and how those goals are achieved 
within a given organization. In these settings, participants' sense of purpose and whether they could offer a contribution influenced the extent to which they felt that they belonged in that space.

For instance, Christina reflected that joining the fashion magazine club her freshman year was sometimes "really uncomfortable" because "it was like kind of going back into the classroom and feeling different ... Most of the committee members are predominantly White students so I felt like I could never fit in.” Though this was challenging, Christina continued going to meetings "just hoping I would be more involved" because of "the reputation that the magazine had and I really just wanted to be involved in my major." However she was rarely given the opportunity to contribute in a meaningful way. Christina recalled, "Most of the time I was there just sitting and hearing the updates." By her second semester she was still unable to contribute and decided to leave the organization.

Christina's experience in the magazine club was in stark contrast

to her sorority experience where I always felt like what I have to say matters and like I hope all my other sisters do too, but we do not ever try to make someone feel like oh you what you say doesn't matter because everyone is a part of the sisterhood so everyone's voice matters.

Likewise, once all participants were part of the sororities and fraternities they assumed meaningful roles and responsibilities within the organizations that caused them to feel valued and a sense of belonging. The fact that membership in the Latina/o sororities and fraternities was typically small (15 members or less) provided ample opportunities for participants to become involved, or as Davina described, "basically everybody in the chapter has a position." For Lori, the fact that she had something to contribute to the meetings because of her responsibility as a chair was also an important part of her belonging in that space. She described that when "it's your turn to talk ... the sisters, they listen to you and ask questions . . . It gives you a sense of authority." In that space, "I can really say my opinion and it will matter."

Hector described his responsibility in the fraternity as well as the role of his brothers in terms of keeping one another "connected, 
accountable, keeping each other in check and making sure we're ok. In case one of us disappears, [we question] Where is he at?" He also explained that when the brothers plan and host events they "do it together, we don't do it separately, we come together and bring up ideas and just make it happen." The essence of the fraternity as a collaborative effort was important in ensuring everyone had a role or responsibility.

\section{Where I Share Interests or Values With Others}

Participants often identified particular places or groups in which sharing values or interests with those in the setting influenced their sense of belonging-a reflection of both the aggregate and socially constructed environments (Strange \& Banning, 2015). For instance, Karla felt a strong sense of belonging with the marching band at Clearview. She emphasized that the community is "so passionate about Clearview football." Being able to be part of the school's excitement and spirit for the team, Karla thought "it's nice to have that connection with so many people that like something."

Within the Latina/o sororities and fraternities, "where I share interests or values with others" often connected with participants' cultural interests and values and therefore overlapped with "where people look like me" and "where my racial identity and culture is valued." Importantly, these shared interests and values provided a foundation as members planned organizational events and initiatives such as fundraising, sisterhood/brotherhood, social, philanthropic, and cultural events and served as a defining characteristic of these groups as collective cultural agents (Museus \& Quaye, 2009). However, there were also other examples of ways this characteristic manifested in participant experiences within their organizations.

For instance, Nine's sense of belonging as a Kappa Beta was particularly strengthened through their shared knowledge of social justice issues. She explained that they stay current on issues "and are able to talk about it within ourselves like in chapter meetings, we'll be like 'oh did you hear what happened?' . . . we talk about it and are able to like have sisters give their opinion on things like that." Nine added that "a lot of sisters have gone to the national conference on race and ethnicity so we have learned about those things and I think 
we're just all a little more aware." She appreciated having her sisters to discuss these issues and thought that if she did not have them, "I wouldn't have anyone else to talk to about and hear other experiences, hear other thoughts and things like that. So I definitely feel a sense of belonging with them especially."

Luis's experience was a primary example of how one characteristic of belonging could be outweighed by others. Although Luis knew his brothers cared for him and supported him, there have been times when he did not feel like he belonged in Zeta Alpha because he had different interests and performed his gender differently than the majority of his brothers. He described,

How I consider myself, well first heterosexual, but at the same time I have a feminine gender expression ... the gender expression is maybe how I act, how I interact with others, or the things I do are just not stereotypical hypermasculine or alpha male. It's just a little away from that maybe more on the feminine side. The sassy Luis who likes to gossip and socialize with friends and just hang around or maybe go shopping or go on cruises and all that stuff or to travel and all that stuff. Just things that are just maybe not stereotypical with men. That's who I am and maybe why I do not fit in as well.

Luis explained that the "majority" of his brothers fit the "hypermasculine" stereotype, while in terms of his interests,

I'm the type of person who doesn't like to party or go out to drink heavily and all that stuff ... Or also ... Just how the majority of the guys like to play soccer, I hate sports. Or how they like to work out. I hate working out (laughs). How they like to play video games, I hate video games.

Because of these differences Luis has "had those moments where I feel like I don't belong." However his sense of belonging was reconfirmed after attending the fraternity's national convention over the summer. He met another member from a chapter in a different state who he asserted was his "twin." Luis noted that in terms of their personalities 
they were "just the same-feminine gender expression, Latino male heterosexual. Going through similar childhood experiences, low-income student, first in family to go to college, and just a lot of other things that made us similar." Meeting another brother that shared so many characteristics reminded Luis why he joined the organization and that it did not matter how he identified because "at the end of the day you're still brothers. At the end of the day everyone values you because you're in it."

\section{Conclusion and Implications}

This research explored the role of involvement in Latina/o sororities and fraternities in how students experience and develop a sense of belonging in PWIs. The results of this study showed that all participants encountered particular settings in which they belonged as well as those in which they did not feel that they belonged. Findings showed that experiences within microsystems (Bronfenbrenner, 1997), including campus subcultures, defined individual sense of belonging within those spaces and often informed institutional belonging. However, macrosystems- "the overarching pattern of micro-, meso-, and exosystems characteristic of a given culture, subculture, or other extended social structure" (Bronfenbrenner, 1997, p. 317)-were much more influential in institutional sense of belonging and rarely played a significant role in students' belonging within subcultures.

Importantly, the differences in how participants described their sense of belonging is notable because even for participants that reported feeling a sense of belonging to the university, many still identified particular microsystems on campus that they did not feel a sense of belonging within. Therefore, although Bronfenbrenner (1997) referred to "school" generally as a microsystem (see p. 312), the results of this study underscored the importance of distinguishing parts of the university as individual microsystems as opposed to a whole. Microsystems such as sorority and fraternity chapter meetings, classes, and student support offices were encountered daily and, as a result, played an important role in sense of belonging. Individuals interacted with elements of microsystems including the physical, organizational, socially constructed, and human aggregate environments (Strange \& 
Banning, 2015), which defined the extent to which they experienced a sense of belonging within the microsystem. Their experiences within these environments pointed to ways power, privilege, and oppression were institutionalized and perpetuated within campus environments, which ultimately affected their belonging.

The findings of this study focused on the characteristics participants associated with places of belonging. To consider spaces where individuals lacked belonging simply requires a reversal of the five characteristics. Places that lacked compositional diversity; where individuals felt their racial identity and culture were not valued or were actively erased; where the individual was not treated as though they mattered; where they were silenced, ignored, or not given the opportunity to contribute; and where they lacked shared interests with others were likely areas the participants did not feel they belonged. The characteristics of places where participants lacked belonging pointed to overarching patterns of behaviors that marginalized and often erased Students of Color from those spaces.

Based on participants' reflections, it was apparent that experiencing even one characteristic of belonging could positively influence their sense of belonging within a particular microsystem. However two characteristics of belonging, "where people look like me" and "where my racial identity and culture is recognized and valued," were particularly influential in Latina/o college student sense of belonging. As a result, experiences of marginalization and mattering that participants experienced on campus that were connected to their racial/ ethnic identities played strong roles in their sense of belonging at the institutional level, pointing to the role of the macrosystem in institutional belonging. Therefore, it was perhaps unsurprising that the five participants that reported a lack of belonging to the institution or that their belonging at the institutional level was murky were all from Plains University, which participants described as a much more hostile climate for diversity compared to Clearview.

Based on the participants' experiences and aligning with previous literature (Attinasi, 1989; Kuh \& Love, 2000; Museus \& Quaye, 2009), it was clear that campus subcultures played a critical role in Latina/o sense of belonging within the institution. Some individuals only experienced a sense of belonging in particular microsystems, many of which stemmed from their involvement in Latina/o sororities and 
fraternities. Regardless of whether individuals reported a sense of belonging at the institutional level, all participants expressed that they would not feel a sense of belonging at their respective university without being involved in their sorority, fraternity, or a different subcommunity within the institution. Paloma eloquently described the significance of being part of a subculture, "You want to be part of the communities where you belong ... it makes you have a home away from home ... somewhere you can be yourself, somewhere you can express yourself however you want and people are still going to love you."

Although all of the participants felt a sense of belonging within their sorority or fraternity, it is important to note that these spaces can present challenges for students with different marginalized identities. In Luis's experience, his gender performance did not align with the expectations and behaviors of his brothers, which caused him to question his belonging within his fraternity. Luis's experience is reflected in previous literature on ways siloed identity spaces can serve one aspect of an individual's identity while further marginalizing others (Blockett, 2017; Duran \& Pérez, 2019). This finding carries implications for practice in terms of ensuring that members of organizations are engaged in conversations around gender and sexuality and how heteronormativity and gendered expectations affect members' experiences within the organizations. Furthermore, while some national organizations are engaging in conversations around transgender members, organizations should bring these conversations to the forefront if they truly hope to serve all Latina/o/x college students.

These findings point to other vital implications for practice in serving Latina/o/x college students. The centrality of the characteristics "where people look like me" and "where my racial identity and culture is recognized and valued" in participants' sense of belonging underscored the influential role that ethnic-based student organizations, and Latina/o sororities and fraternities specifically, may have on college students as they navigate predominantly White institutions. Thus, institutions should ensure that ethnic-based organizations are available to students on campus and that students are encouraged to explore the option of joining such organizations. In addition, institutions should carefully consider whether ethnic-based organizations including Latina/o sororities and fraternities are provided supports 
necessary to ensure these groups not only exist on campus, but that they can thrive. Furthermore, institutions should seek ways to centralize and celebrate the racial identities and culture of Students of Color on campus. Although it is helpful for institutions to support student organizations as they host events, students should not have to bear all of the labor in cultivating climates for diversity.

Additionally, the challenges participants faced navigating a predominantly White institutional environment as well as the interactions they experienced with members of the community pointed to the need for increased awareness regarding racial dynamics on campus. As discussed within the findings, feelings of marginalization and belonging were amplified and mitigated through interactions with others within the space, thus members of the campus community play an important role in the experiences of Students of Color. Therefore, institutions should take steps to increase awareness of issues pertaining to equity and inclusion for members of the campus community as a whole. These conversations should go beyond simply recognizing the benefits of diversity to critically examining ways privilege and power are institutionalized and form structures that serve to oppress individuals with minoritized identities. Yet while institutions should focus on cultivating climates of inclusion, they should also better prepare Students of Color entering predominantly White institutions for their campus experience. Similar to all participants, Fernando described that transitioning to a PWI was "shocking because the population, like you don't really see People of Color here.” As Juan noted, helping students to recognize the realities of the student demographics on campus as opposed to relying on inaccurate representations based on photos featured on institutional websites could help decrease the shock students experience during the transition process.

As in all research, there were several limitations to this work that have important implications for future research. First, this particular study focused on Latina/o student sense of belonging in order to limit the scope of the research to gain a clear understanding of how this dynamic manifests in Latina/o student experiences. However the literature on campus subcultures also points to the need for research that examines sense of belonging in the experiences of all Students of Color. Therefore future studies should also extend beyond the Latina/o community to center the experiences of students with 
other racial/ethnic identities. In addition, another intentional delimitation of this study meant that all of the participants were members of Latina/o sororities and fraternities. While these individuals were purposefully selected for what they could reveal concerning this particular phenomenon, the unique features of Latina/o sororities and fraternities may limit the transferability of the findings in this study to other types of subcultures. Future studies could explore the role of subcultures in relation to Latina/o student sense of belonging outside of these organizations.

Furthermore, the historical exclusion of individuals that do not identify in the gender binary from FSL organizations limited this study to focus on the Latina/o experience. Future studies should further explore the experiences of the Latinx student population in terms of sense of belonging as well as continue to interrogate the ramifications of these exclusionary practices within FSL. Future studies should also further examine ways these silo-identitied spaces operate in the experiences of Queer Latina/o/x members.

Additionally, while this study provided insight to Latina/o student experiences at large, public, predominantly White institutions, future studies could explore how sense of belonging unfolds in different institutional types. Finally, the findings of this study also point to the need for future work to further untangle the complexities of sense of belonging at macro and micro levels. Distinguishing between levels of student sense of belonging is an important distinction because it calls attention to the question of whether particular areas of the university, or even the university culture as a whole, are inclusive and equitable.

\section{References}

Atkinson, E., Dean, L. A., \& Espino, M. M. (2010). Leadership outcomes based on membership in Multicultural Greek Council (MGC) organizations. Oracle: The Research Journal of the Association of Fraternity/Sorority Advisors, 5, 34-48.

Attinasi, L. C., Jr. (1989). Getting in: Mexican Americans' perceptions of university attendance and the implications for freshman year persistence. The Journal of Higher Education, 6o, 247-277. http://dx.doi.org/10.1080/00221546.1989.117 75035

Blockett, R. A. (2017). 'I think it's very much placed on us': Black queer men laboring to forge community at a predominantly White and (hetero) cisnormative research institution. International Journal of Qualitative Studies in Education, 30, 800-816. http://dx.doi.org/10.1080/09518398.2017.1350296 
Bronfenbrenner, U. (1995). Developmental ecology through space and time: A future perspective. In P. Moen, G. H. Elder, Jr., \& K. Luscher (Eds.), Examining lives in context: Perspectives on the ecology of human development (pp. 619647). Washington, DC: American Psychological Association. http://dx.doi. org/10.1037/10176-018

Bronfenbrenner, U. (1997). The ecology of cognitive development: Research models and fugitive findings. In K. Arnold \& I. Carreiro King (Eds.), College student development and academic life (pp. 295-336). New York, NY: Garland Publishing.

Charmaz, K. (2000). Grounded theory: Objectivist and constructivist methods. In N. K. Denzin \& Y. S. Lincoln (Eds.), Handbook of qualitative research (2nd ed., pp. 509-535). Thousand Oaks, CA: SAGE.

Charmaz, K. (2006). Constructing grounded theory: A practical guide through qualitative analysis. Thousand Oaks, CA: SAGE.

Clark-Ibáñez, M. (2004). Framing the social world with photo-elicitation interviews. American Behavioral Scientist, 47, 1507-1527. http://dx.doi. org/10.1177/0002764204266236

Creswell, J. W. (2013). Qualitative inquiry \& research design: Choosing among five approaches (3rd ed.). Thousand Oaks, CA: SAGE.

Delgado-Guerrero, M., \& Gloria, A. M. (2013). La importancia de la hermandad Latina: Examining the psychosociocultural influences of Latina-based sororities on academic persistence decisions. Journal of College Student Development, 54, 361-378. http://dx.doi.org/10.1353/csd.2013.0067

D’Souza, D. (1991). The new segregation on campus. The American Scholar, 6o, 17-30.

Dueñas, M., \& Gloria, A. M. (2017). ¿Pertenezco a esta universidad?: The mediating role of belonging for collective self-esteem and mattering for Latin@ undergraduates. Journal of College Student Development, 58, 891-906. http:// dx.doi.org/10.1353/csd.2017.0070

Duran, A., \& Pérez, D. I. I., II. (2019). The multiple roles of chosen familia: Exploring the interconnections of queer Latino men's community cultural wealth. International Journal of Qualitative Studies in Education, 32, 67- 84. http://dx.doi.org/10.1080/09518398.2018.1523484

Freeman, T. M., Anderman, L. H., \& Jensen, J. M. (2007). Sense of belonging in college freshmen at the classroom and campus levels. Journal of Experimental Education, 75, 203-220. http://dx.doi.org/10.3200/JEXE.75.3.203-220

Gloria, A. M., Castellanos, J., \& Orozco, V. (2005). Perceived educational barriers, cultural fit, coping responses, and psychological well-being of Latina undergraduates. Hispanic Journal of Behavioral Sciences, 27, 161-183. http:// dx.doi.org/10.1177/0739986305275097

González, K. P. (2002). Campus culture and the experiences of Chicano students in a predominantly White university. Urban Education, 37, 193-218. http:// dx.doi.org/10.1177/0042085902372003 
Guardia, J. R., \& Evans, N. J. (2008). Factors influencing the ethnic identity development of Latino fraternity members at a Hispanic serving institution. Journal of College Student Development, 49, 163-181. http://dx.doi.org/10.1353/ csd.0.0011

Hagerty, B. M. K., Williams, R. A., Coyne, J. C., \& Early, M. R. (1996). Sense of belonging and indicators of social and psychological functioning. Archives of Psychiatric Nursing, 10, 235-244. http://dx.doi.org/10.1016/ $\underline{\text { So883-9417(96)80029-X }}$

Harper, D. (2002). Talking about pictures: A case for photo elicitation. Visual Studies, 17, 13-26. http://dx.doi.org/10.1080/14725860220137345

Hausmann, L. R. M., Schofield, J. W., \& Woods, R. L. (2007). Sense of belonging as a predictor of intentions to persist among African American and White firstyear college students. Research in Higher Education, 48, 803-839. http:// dx.doi.org/10.1007/s11162-007-9052-9

Hurtado, S., \& Carter, D. F. (1997). Effects of college transition and perceptions of the campus racial climate on Latino college students' sense of belonging. Sociology of Education, 70, 324-345. http://dx.doi.org/10.2307/2673270

Hurtado, S., \& Ponjuan, L. (2005). Latino educational outcomes and the campus climate. Journal of Hispanic Higher Education, 4, 235-251. http://dx.doi. org/10.1177/1538192705276548

Imenda, S. (2014). Is there a conceptual difference between theoretical and conceptual frameworks? Journal of Social Sciences, 38, 185-195. http://dx.doi. org/10.1080/09718923.2014.11893249

Inkelas, K. K. (2004). Does participation in ethnic cocurricular activities facilitate a sense of ethnic awareness and understanding? A study of Asian Pacific American undergraduates. Journal of College Student Development, 45, 285302. http://dx.doi.org/10.1353/csd.2004.0037

Johnson, D. R., Soldner, M., Leonard, J. B., Alvarez, P., Inkelas, K. K., RowanKenyon, H. T., \& Longerbeam, S. D. (2007). Examining sense of belonging among first-year undergraduates from different racial/ ethnic groups. Journal of College Student Development, 48, 525-542. http://dx.doi.org/10.1353/ csd.2007.0054

Kim, Y. K., Park, J. J., \& Koo, K. K. (2015). Testing self-segregation: Multiple-group structural modeling of college students' interracial friendship by race. Research in Higher Education, 56, 57-77. http://dx.doi.org/10.1007/s11162-014-9337-8

Kiyama, J. M., Museus, S. D., \& Vega, B. E. (2015). Cultivating campus environments to maximize success among Latino and Latina college students. New Directions for Higher Education, 2015(172), 29-38. http://dx.doi. org/10.1002/he.20150

Kuh, G. D., \& Love, P. G. (2000). A cultural perspective on student departure. In J. M. Braxton (Ed.), Reworking the student departure puzzle (pp. 196-212). Nashville, TN: Vanderbilt University Press.

Locks, A. M., Hurtado, S., Bowman, N. A., \& Oseguera, L. (2008). Extending notions of campus climate and diversity to students' transition to college. 
The Review of Higher Education, 31(3), 257-285. http://dx.doi.org/10.1353/ rhe.2008.0011

Luedke, C. L. (2018). "Es como una familia": Bridging emotional support with academic and professional development through the acquisition of capital in Latinx student organizations. Journal of Hispanic Higher Education, 1-17. http://dx.doi.org/10.1177/1538192717751205

Maxwell, J. A. (2013). Qualitative research design: An interactive approach (3rd ed.). Thousand Oaks, CA: SAGE.

Merriam, S. B. (2001). Qualitative research and case study applications in education: Revised and expanded from case study research in education. San Francisco, CA: Jossey-Bass.

Merriam, S. B., \& Tisdell, E. J. (2016). Qualitative research: A guide to design and implementation (4th ed.). San Francisco, CA: Jossey-Bass.

Miles, M. B., Huberman, A. M., \& Saldaña, J. (2014). Qualitative data analysis: A methods sourcebook (3rd ed.). Thousand Oaks, CA: SAGE.

Moore, T. S., Lapan, S. D., \& Quartaroli, M. T. (2012). Case study research. In S. D. Lapan, M. T. Quartaroli, \& F. J. Riemer (Eds.), Qualitative research: An introduction to methods and designs (pp. 243-270). San Francisco, CA: Jossey-Bass.

Moreno, D. R. (2012). The influence of a Latina-based sorority on the academic experiences of Latina college students (Unpublished master's thesis). University of Southern California, Los Angeles, CA.

Muñoz, S. M., \& Guardia, J. R. (2009). Nuestra historia y futuro (our history and future): Latino/a fraternities and sororities. In C. L. Torbenson \& G. S. Parks (Eds.), Brothers and sisters: Diversity in college fraternities and sororities (pp. 104-132). Madison, NJ: Fairleigh Dickinson University Press.

Museus, S. D. (2008a). Focusing on institutional fabric: Using campus culture assessments to enhance cross-cultural engagement. In S. R. Harper (Ed.), Creating inclusive environments for cross-cultural learning and engagement in higher education (pp. 205-234). Washington, DC: National Association of Student Personnel Administrators.

Museus, S. D. (2008b). The role of ethnic student organizations in fostering African American and Asian American students' cultural adjustment and membership at predominantly White institutions. Journal of College Student Development, 49, 568 -586. http://dx.doi.org/10.1353/csd.0.0039

Museus, S. D., \& Maramba, D. C. (2011). The impact of culture on Filipino American students' sense of belonging. The Review of Higher Education, 34, 231-258. http://dx.doi.org/10.1353/rhe.2010.0022

Museus, S. D., \& Quaye, S. J. (2009). Toward an intercultural perspective of racial and ethnic minority college student persistence. The Review of Higher Education, 33, 67-94. http://dx.doi.org/10.1353/rhe.0.0107

Nuñez, A.-M. (2009). Latino students' transition to college: A social and intercultural capital perspective. Harvard Educational Review, 79, 22-48. http://dx.doi.org/10.17763/haer.79.1.wh7164658k33w477 
Rosenberg, M., \& McCullough, B. C. (1981). Mattering: Inferred significance to parents and mental health among adolescents. Research in Community and Mental Health, 2, 163-182.

Ryan, C. L., \& Bauman, K. (2016). Educational attainment in the United States: 2015. Population characteristics: Current population reports (No. P2O-578). Washington, DC: U.S. Census Bureau. Retrieved from https://www.census.gov/ content/dam/Census/library/publications/2016/demo/p20-578.pdf

Saldaña, J. (2016). The coding manual for qualitative researchers (3rd ed.). Thousand Oaks, CA: SAGE.

Sanchez, S. M. (2011). First-generation Latino males in Latino fraternities at a predominantly White institution: Psychological, social, and cultural college experiences (Unpublished doctoral dissertation). University of Southern California, Los Angeles, CA.

Schlossberg, N. K. (1989). Marginality and mattering: Key issues in building community. New Directions for Student Services, 1989(48), 5-15. http://dx.doi. org/10.1002/ss.37119894803

Sidanius, J., Van Laar, C., Levin, S., \& Sinclair, S. (2004). Ethnic enclaves and the dynamics of social identity on the college campus: The good, the bad, and the ugly. Journal of Personality and Social Psychology, 87, 96-110. http://dx.doi. org/10.1037/0022-3514.87.1.96

Spanierman, L. B., Soble, J. R., Mayfield, J. B., Neville, H. A., Aber, M., Khuri, L., \& De La Rosa, B. (2013). Living learning communities and students' sense of community and belonging. Journal of Student Affairs Research and Practice, 50, 308-325. http://dx.doi.org/10.1515/jsarp-2013-0022

Stake, R. E. (2006). Multiple case study analysis. New York, NY: Guilford Press.

Strange, C. C., \& Banning, J. H. (2015). Designing for learning: Creating campus environments for student success (2nd ed.). San Francisco, CA: Jossey-Bass.

Strayhorn, T. L. (2008). Sentido de pertenencia: A hierarchical analysis predicting sense of belonging among Latino college students. Journal of Hispanic Higher Education, 7, 301-320. http://dx.doi.org/10.1177/1538192708320474

Strayhorn, T. L. (2012). College students' sense of belonging: A key to educational success for all students. New York, NY: Routledge. http://dx.doi. org/10.4324/9780203118924

Torbenson, C. L. (2005). The origin and evolution of college fraternities and sororities. In T. L. Brown, G. S. Parks, \& C. M. Phillips (Eds.), African American fraternities and sororities: The legacy and the vision (pp. 37-66). Lexington, KY: University Press of Kentucky.

Vaccaro, A., \& Newman, B. M. (2016). Development of a sense of belonging for privileged and minoritized students: An emergent model. Journal of College Student Development, 57, 925-942. http://dx.doi.org/10.1353/csd.2016.0091

Villalpando, O. (2003). Self-segregation or self-preservation? A critical race theory and Latina/o critical theory analysis of a study of Chicana/o college students. International Journal of Qualitative Studies in Education, 16, 619-646. http://dx.doi.org/10.1080/0951839032000142922 